\title{
Symptoms of asthma, bronchial responsiveness and atopy in immigrants and emigrants in Europe
}

\author{
A. Tobias*,\#, J.B. Soriano*, , S. Chinn ${ }^{+}$, J.M. Anto*,§, J. Sunyer*, P. Burney ${ }^{+}$, for the European \\ Community Respiratory Health Survey
}

Symptoms of asthma, bronchial responsiveness and atopy in immigrants and emigrants in Europe. A. Tobias, J. B. Soriano, S. Chinn, J.M. Anto, J. Sunyer, P. Burney, for the European Community Respiratory Health Survey. C) ERS Journals Ltd 2001.

ABSTRACT: Migration studies on asthma may provide information on its environmental causes. The European Community Respiratory Health Survey has potential advantages due to the number of countries involved, standardized collection of information, assessment of directionality of migration, and availability of physiological data on bronchial responsiveness and atopy.

Prevalence rates of symptoms associated with asthma were compared for immigrants, emigrants and nonmigrants living in centres mostly in western Europe. Similar analyses were carried out for bronchial responsiveness (provocative concentration causing a $20 \%$ fall in forced expiratory volume in one second and slope) and atopy. Medication and use of health services were also explored.

Overall, $1,678(8.6 \%)$ of 19,516 participants were immigrants in the 18 countries participating in the study, of whom 581 were emigrants from one of the participating countries. Rates of asthma symptoms were higher in immigrants (odds ratio (OR): 1.21, 95\% confidence interval (CI): 1.00-1.51) and emigrants (OR: 1.31, 95\% CI: 0.96-1.51) compared to nonmigrants after controlling for area, sex, age and smoking status. However, bronchial responsiveness and atopy were equally distributed between immigrants, emigrants and nonmigrants. Use of health services was observed to be similar in migrants and nonmigrants with asthma.

In the European Community Respiratory Health Survey, migrants reported more asthma symptoms, but had similar bronchial responsiveness, atopy, and use of health services when compared with the nonmigrant population.

Eur Respir J 2001; 18: 459-465.

\begin{abstract}
*Respiratory and Environmental Health Research Unit, IMIM, Barcelona, Spain, ${ }^{\#}$ Dept of Clinical Epidemiology and Public Health, Hospital de la Santa Creu i Sant Pau, Barcelona, Spain, "Worldwide Epidemiology, GlaxoSmithKline R and D, Greenford, Middlesex, UK, 'Dept of Public Health Sciences, Guy's, King's and St. Thomas' School of Medicine, Guy's Hospital, London, UK and ${ }^{8}$ Dept of Experimental and Health Sciences, Universitat Pompeu Fabra (UPF), Barcelona, Spain.
\end{abstract}

Correspondence: P. Burney, Dept of Public Health Sciences, Kings College, 5th floor Capital House, 42 Weston Street, London SE1 3QD, UK. Fax: 44207846605

Keywords: Asthma atopy

bronchial responsiveness

European Community Respiratory

Health Survey

healthcare

migration

Received: March 202000

Accepted after revision May 142001
Migrants may have a greater susceptibility to asthma [1]. Variations in the prevalence of disease and increased rates associated with time, migration and changing lifestyle highlight the importance of environmental agents in the induction of the disease [2]. Compared with studies of cancer and cardiovascular disease, international migrant studies of asthma are scarce and very localized, tending to compare immigrants only with the host populations. Immigrants may suffer from psychological changes including somatization due to post-traumatic stress disorder and other anxiety disorders [3]. As with the unemployed [4], migrants might lack access to medical care, as well as being more susceptible to respiratory and other conditions.

The European Community Respiratory Health Survey (ECRHS) has previously provided information on the distribution of asthma and asthma-related phenotypes in the 20-44-yr-old population within
Europe and elsewhere [5-7]. To study the effects of migration on asthma, the ECRHS has potential advantages: data from 14 European and four other countries, standardized information including direction of migration, and physiological data on atopy and bronchial responsiveness.

By means of a cross-sectional analysis of the ECRHS, the authors have compared prevalence rates of asthma symptoms, bronchial responsiveness, atopy and use of health services by those with asthma in first-generation immigrants and emigrants, and nonmigrants.

\section{Methods}

Study design and sample

The study design, methodology and objectives of the ECRHS have been described elsewhere [5]. Briefly, 
the ECRHS was conducted in 38 areas of 18 countries from 1991-1993. A random sample of 3,000 males and females aged 20-44 yrs from each of the participating areas was contacted and requested to complete a short screening questionnaire on respiratory symptoms. Subsequently, a 20\% random sample $(n=19,516)$ of the source population was asked to complete a long questionnaire, provide blood samples, undergo skin and forced spirometric tests, and have bronchial responsiveness measured through a methacholine challenge test [7].

\section{Migration and social data}

Information on country of birth and country of residence was self-reported by participants. Immigrants were defined as those subjects who were not born in their current country of residence. A subsample of them were also considered to be emigrants, as they were born in one of the participating countries. Others were considered to be nonmigrants. Social class was defined as manual, nonmanual and other (including unemployed and housewives) as presented elsewhere [8].

Countries were stratified into zones according to whether they had a high, medium or low prevalence of asthma among nonmigrants. The groups were as follows: high: Australia, France, New Zealand, UK, USA; Medium: Denmark, Ireland, Italy, Sweden, Switzerland; low: Belgium, Germany, Iceland, Netherlands, Norway, Spain. India and Estonia had virtually no migrants and were excluded from these analyses.

\section{Symptoms questionnaire, respiratory function and immunological measurements}

Any individual was considered symptomatic of asthma if he/she answered yes to any of the following questions of the long questionnaire: "Have you been woken by an attack of shortness of breath in the last 12 months?", "Have you had an attack of asthma during the last 12 months?", or "Are you currently taking medicines for asthma?". For the assessment of smoking status, participants were asked whether they had smoked at least one cigarette a day, one cigar a week for $1 \mathrm{yr}$ or $360 \mathrm{~g}$ tobacco in a lifetime [9]. The subjects were categorized into three groups: nonsmokers, exsmokers and current smokers.

Bronchial responsiveness was defined as a provocative concentration causing a $20 \%$ fall in forced expiratory volume in one second (FEV1) (PD20) from the largest postdiluent volume during methacholine challenge with an estimated cumulative dose of $5.1 \mu \mathrm{mol}$ methacholine [7]. Because many participants will have censored data on bronchial responsiveness as measured by PD20, analysis was also carried out by calculating the slope, or regression coefficient of percentage decline in FEV1 with log dose [7].

Atopy was assessed by means of serum-specific immunoglobulin-E (IgE) [6]. A participant was considered as having a measurable specific serum $\operatorname{IgE}$ when he/she had a specific IgE $>0.35 \mathrm{kU} \cdot \mathrm{L}^{-1}$ by the
Pharmacia CAP method (Pharmacia Diagnostics, Uppsala, Sweden) to any of the following allergens: Dermatophagoides pteronyssinus, timothy grass, cat, Cladosporium, or a local allergen. The local allergen was birch for northern Europe, Parietaria for southern Europe and ragweed for the USA, New Zealand and Australia.

\section{Medication and use of health services}

Use of respiratory medications during the last year was estimated for inhaled, oral and other medicines. Inhaled medicines included $\beta_{2}$-agonists, nonspecific $\beta$-agonists, antimuscarinics, steroids, compound bronchodilators and other inhalers. Oral medicines included $\beta_{2}$-agonists, nonspecific $\beta$-agonists, antimuscarinic drugs, methylxanthines, steroids, antihistamines, and bronchodilators. Finally, other respiratory medications included vaccines, injections, suppositories, and other remedies. Participants were also asked if medication was prescribed by a doctor, and the frequency of taking medication, namely every day or only for attacks of breathlessness. The use of health services for any respiratory problem, frequency of medication and the type of medical practitioner last contacted were recorded. All analyses on the use of health care services focused only on subjects reporting symptoms associated with asthma.

\section{Statistical analysis}

The statistical analysis was done using Stata (StataCorp., College Station, TX, USA) [10]. The Chi-squared test was used in the univariate analysis. Multinomial logistic regression [11] was applied to obtain adjusted odds ratios (OR) and their 95\% confidence intervals (CI) by country of residence. Regression models were adjusted for sex, age (categorized into five groups, 20-24, 25-29, 30-34, 35-39 and 40-45 yrs), social class and smoking status. Random effects meta-analysis was used to pool the results over countries and test for heterogeneity [12].

\section{Results}

\section{Migration rates}

There were 1,678 immigrants in the present study, constituting $8.6 \%$ of the ECRHS study population. Overall, $581(3.0 \%)$ were born in one of the participating countries, therefore being considered emigrants from these countries.

Migration rates varied widely between countries, the centres of the USA $(27.9 \%)$, Switzerland $(22.4 \%)$ and Australia $(20.5 \%)$ had the highest rates of immigrants observed, while those of Italy (1.3\%), Spain $(2.0 \%)$ and Iceland $(2.1 \%)$ had the lowest. India and Estonia had practically no immigrants, and therefore were excluded in the analyses. There were statistically significant differences in the rates of migration by age groups $(\mathrm{p}<0.01)$, the oldest group 
(40-45 yrs) having the highest rate of migration $(10.7 \%)$ and social class, with a higher percentage of manual class workers among immigrants than nonmigrants. There were no statistically significant differences in the rates of migration by sex or smoking status (table 1).

\section{Symptoms in migrants}

Higher prevalence rates of asthma symptoms were reported by immigrants $(11.2 \%)$ and emigrants $(11.0 \%)$ than nonmigrants $(8.6 \%)$, both differences being statistically significant $(\mathrm{p}<0.01)$. The corresponding ORs adjusted by sex, age, and smoking were $1.21(95 \%$ CI: $1.00-1.51)$ in immigrants and 1.31 (95\% CI: 0.96-1.78) in emigrants compared to nonmigrants (table 2). Risk estimates could be considered homogeneous between countries for immigrants (Chi-squared test for heterogeneity $=12.22$, degrees of

Table 1.-Description of the study population by migration status

Nonmigrants Immigrants Emigrants

\begin{tabular}{|c|c|c|c|}
\hline \multicolumn{4}{|c|}{ Country of residence* } \\
\hline Australia & 532 & 137 & 20 \\
\hline Belgium & 1080 & 42 & 14 \\
\hline Denmark & 372 & 22 & 9 \\
\hline Estonia & 431 & 0 & 1 \\
\hline France & 1866 & 259 & 29 \\
\hline Germany & 1939 & 44 & 93 \\
\hline Iceland & 550 & 12 & 3 \\
\hline India & 592 & 1 & 17 \\
\hline Ireland & 410 & 44 & 11 \\
\hline Italy & 882 & 12 & 69 \\
\hline Netherlands & 1193 & 54 & 24 \\
\hline New Zealand & 1011 & 243 & 11 \\
\hline Norway & 784 & 51 & 18 \\
\hline Spain & 1902 & 40 & 31 \\
\hline Sweden & 1650 & 206 & 14 \\
\hline Switzerland & 662 & 191 & 11 \\
\hline UK & 1461 & 118 & 173 \\
\hline USA & 521 & 202 & 33 \\
\hline \multicolumn{4}{|l|}{ Sex } \\
\hline M & $8483(48)$ & $781(47)$ & $292(50)$ \\
\hline $\mathrm{F}$ & $9355(52)$ & $897(53)$ & $289(50)$ \\
\hline \multicolumn{4}{|l|}{ Age yrs* } \\
\hline $20-25$ & 3064 (17) & $180(11)$ & $58(10)$ \\
\hline $25-30$ & $3517(20)$ & 247 (15) & 85 (15) \\
\hline $30-35$ & $3513(20)$ & $361(22)$ & $115(20)$ \\
\hline $35-40$ & $3487(20)$ & $379(23)$ & $125(22)$ \\
\hline $40-45$ & 4257 (24) & $511(30)$ & $198(34)$ \\
\hline \multicolumn{4}{|l|}{ Smoking status ${ }^{\#}$} \\
\hline Non & $7853(44)$ & $706(45)$ & $255(44)$ \\
\hline Current & $6349(36)$ & $535(34)$ & $202(35)$ \\
\hline Ex & $3571(20)$ & $326(21)$ & $121(21)$ \\
\hline \multicolumn{4}{|l|}{ Social class*,\# } \\
\hline Nonmanual & $8476(61)$ & $591(61)$ & $316(66)$ \\
\hline Manual & $4195(30)$ & 317 (33) & $145(30)$ \\
\hline Others & $1174(8)$ & $54(6)$ & $17(4)$ \\
\hline Total & $17838(100)$ & $1678(100)$ & $581(100)$ \\
\hline
\end{tabular}

Data are presented as $\mathrm{n}$ and $\mathrm{n}(\%)$. M: male; F: female.

\#: Some figures do not add to totals due to nonresponse.

$*: \mathrm{p}<0.05$. freedom $(\mathrm{df})=14, \mathrm{p}=0.59)$ and for emigrants (Chisquared $=11.79, \quad \mathrm{df}=10, \mathrm{p}=0.30$ ), being significantly different only for immigrants to Australia (OR: 2.18, 95\% CI: 1.25-3.80) and for emigrants from Germany (OR: 2.08, 95\% CI: 1.07-4.05) and New Zealand (OR: 6.10, 95\% CI: 1.79-20.69).

\section{Country of birth and country of residence}

In table 3, an analysis is presented by the country of residence and the country of birth of the migrants, stratifying the countries by whether they had a high, medium or low prevalence of asthma. Despite small figures in some cells, it can be seen that no pattern is observed, and that migrants moving from a high to low country or a low to high country show no consistent pattern. Similarly, emigrants from South America, Asia or Africa yielded no pattern.

\section{Bronchial responsiveness and atopy}

Similar prevalence rates of bronchial responsiveness (14.2\% for immigrants, $15.0 \%$ for emigrants and $14.4 \%$ for nonmigrants) and atopy (40.6\% for immigrants, $37.6 \%$ for emigrants and $38.8 \%$ for nonmigrants) were observed. Overall, migration did not modify the risk of either bronchial responsiveness or atopy (table 4). The OR of having bronchial responsiveness adjusted by sex, age and smoking was 0.90 (95\% CI: $0.74-1.19)$ in immigrants and 1.03 (95\% CI: $0.74-1.43)$ in emigrants compared to nonmigrants. Analysis of slope, instead of PD20, gave similar results. Similarly, the OR of having atopy adjusted by sex, age and smoking was 0.93 (95\% CI: 0.79-1.11) in immigrants and 0.88 (95\% CI: $0.67-1.14)$ in emigrants compared to nonmigrants.

\section{Use of health services}

Finally, the association between migration and use of medication in the last year, and use of health services, was explored in the individuals who reported symptoms associated with asthma (table 5). An approximately similar proportion of immigrants, emigrants and nonmigrants with asthma symptoms had taken inhaled and other medications, although symptomatic immigrants had an increased prevalence of oral medication use, compared to nonmigrants (OR: 1.41, 95\% CI: 1.001-1.99). Immigrants and emigrants, considered separated or grouped, showed no consistent differences in the frequency of medication, the type of practitioner last contacted for breathing problems, or visits to hospital. Compared to nonmigrants, migrants were more likely to be taking oral medication, medicines every day, and medicines only for attacks of breathlessness. Access to health care, as indicated by prescriptions, visits to the doctor or admissions to hospitals yielded ORs close to unity. 
Table 2. - Adjusted odds ratios (ORs), by area, sex, age and smoking status for asthma symptoms among immigrants and emigrants compared to nonmigrants (reference group), by country

\begin{tabular}{|c|c|c|c|c|c|}
\hline \multirow[t]{2}{*}{ Country } & \multicolumn{3}{|c|}{ Asthma no:yes } & \multicolumn{2}{|c|}{ OR $(95 \% \mathrm{CI})$} \\
\hline & Nonmigrants & Immigrants & Emigrants & Immigrants & Emigrants \\
\hline Australia & 478:54 & $114: 23$ & $17: 3$ & $2.18(1.25-3.80)^{*}$ & $1.59(0.44-5.70)$ \\
\hline Belgium & 1004:73 & $37: 5$ & $14: 0$ & $1.86(0.70-4.94)$ & $\mathrm{nc}$ \\
\hline Denmark & $338: 34$ & $21: 1$ & $9: 0$ & $0.54(0.07-4.27)$ & $\mathrm{nc}$ \\
\hline France & 1660:206 & $226: 33$ & $24: 5$ & $1.33(0.89-2.00)$ & $1.77(0.66-4.73)$ \\
\hline Germany & $1828: 111$ & $41: 3$ & $82: 11$ & $1.27(0.38-4.17)$ & $2.08(1.07-4.05)^{*}$ \\
\hline Iceland & $531: 17$ & 11:0 & $3: 0$ & $\mathrm{nc}$ & $\mathrm{nc}$ \\
\hline Ireland & $371: 39$ & $26: 2$ & $10: 1$ & $0.71(0.16-3.18)$ & $1.10(0.13-9.51)$ \\
\hline Italy & $800: 82$ & $10: 2$ & $63: 6$ & $2.14(0.45-10.23)$ & $0.85(0.35-2.07)$ \\
\hline Netherlands & 1123:70 & $49: 3$ & $22: 2$ & $1.16(0.35-3.87)$ & $1.39(0.31-6.20)$ \\
\hline New Zealand & $868: 143$ & 211:31 & $6: 5$ & $1.03(0.63-1.69)$ & $6.10(1.79-20.69)^{*}$ \\
\hline Norway & $736: 48$ & $46: 5$ & $16: 2$ & $1.71(0.64-4.58)$ & 1.99 (0.44-9.04) \\
\hline Spain & $1774: 128$ & $34: 4$ & $28: 3$ & $1.69(0.59-4.87)$ & $1.32(0.39-4.45)$ \\
\hline Sweden & $1515: 135$ & $188: 18$ & $14: 0$ & $1.09(0.65-1.83)$ & $\mathrm{nc}$ \\
\hline Switzerland & $606: 56$ & $168: 23$ & 11:0 & $1.56(0.93-2.63)^{\#}$ & $\mathrm{nc}$ \\
\hline UK & $1278: 183$ & $79: 7$ & $159: 19$ & $0.63(0.28-1.38)$ & $0.87(0.51-1.46)$ \\
\hline USA & 461:60 & $32: 3$ & $28: 5$ & $0.67(0.20-2.28)$ & $1.38(0.50-3.77)$ \\
\hline Total & 15371:1439 & $1293: 163$ & $501: 62$ & $1.21(1.00-1.51)^{*}$ & $1.31(0.96-1.78)^{\#}$ \\
\hline
\end{tabular}

CI: confidence interval; nc: model did not achieve convergence due to lack of migrants. ${ }^{*}: \mathrm{p}<0.05$; ${ }^{*}: \mathrm{p}<0.1$.

\section{Discussion}

In this general population study of adults aged 20-45 yrs in Europe, USA, Australia and New Zealand, migrants (both immigrants and emigrants) had a slightly higher prevalence of symptoms associated with asthma than those subjects defined as nonmigrants. The higher prevalence rates in immigrants could not be attributed to other variables such as sex, smoking or social class. There was a wide variation in the use of medication and health services in the previous year, as previously reported in subjects with asthma-related symptoms [13, 14]. However, symptomatic individuals were treated and used health services evenly, irrespective of migration status. When country of birth and current country of residence were

Table 3.-Prevalence of asthma symptoms in migrants grouping by prevalence of asthma zone in nonmigrants

\begin{tabular}{lccc}
\hline & \multicolumn{3}{c}{ Migrant's zone of residence } \\
\cline { 2 - 4 } & High & Medium & Low \\
\hline Overall & & & \\
$\quad$ Migrants & $700(12.8)$ & $563(11.0)$ & $223(7.3)$ \\
$\quad$ Nonmigrants & $3525(12.5)$ & $5885(9.1)$ & $6748(6.1)$ \\
Migrant's zone of birth & & & \\
High & $199(13.6)$ & $102(7.8)$ & $28(10.7)$ \\
Medium & $48(14.6)$ & $39(5.1)$ & $43(4.7)$ \\
Low & $26(15.4)$ & $62(6.5)$ & $24(12.5)$ \\
West Europe & $16(7.1)$ & $52(12.5)$ & $31(15.0)$ \\
South America & $28(6.2)$ & $33(11.5)$ & $26(9.7)$ \\
Asia & $61(17.9)$ & $52(12.1)$ & $35(0.0)$ \\
Africa & $28(16.4)$ & $176(13.5)$ & $20(5.7)$ \\
Not known & $294(8.5)$ & $47(22.6)$ & $16(0.0)$ \\
\hline
\end{tabular}

Data are presented as n (\%). Prevalences of asthma; High: Australia, France, New Zealand, UK, USA; Medium: Denmark, Ireland, Italy, Sweden, Switzerland; Low: Belgium, Germany, Iceland, Netherlands, Norway, Spain. considered together, there was a lower prevalence of asthma in migrants in those areas of medium prevalence than in those areas of high prevalence, however, there was no clear pattern overall.

Although this is compatible with the observations of Strachan et al. [15] and Leung et al. [16] that subjects who migrate tend to adopt the prevalence of the area to which they migrate, the fact that no pattern was observed on the rates of migration to/ from countries where the asthma burden is very high (i.e. English speaking countries) or to/from countries where the asthma burden is lower, and that migration was not associated with higher rates of bronchial responsiveness or atopy, leads the authors to consider the present study as less conclusive.

A number of limitations must be considered, namely nonresponse, sampling, the low number of immigrants and the lack of extended questionnaire data. There was a substantial nonresponse rate in the ECRHS, and despite intense efforts, the participation rate was about $60 \%$ for the long questionnaire and $40-50 \%$ for respiratory and blood tests. However, this lack of response has not necessarily affected the validity of the results. It is unlikely that immigrants were selectively persuaded to participate in the study. Finally, because sampling strategy in each country was from official sources, only legal immigrants may have been included, although there is universal coverage of health benefits in most European countries for legal and illegal immigrants.

One major limiting factor was the low number of immigrants reported in most of the participating countries, leading to a lack of power in analyses particularly when adjusting by confounding variables. There were limited data on migration in the questionnaire, and more specific analyses regarding to when asthma symptoms developed in relation to migration could not be performed.

A potential bias may come from language problems 
Table 4.-Adjusted odds ratios (OR), by area, sex, age and smoking status for bronchial responsiveness and atopy in immigrants and emigrants compared to nonmigrants (reference group) by country

\begin{tabular}{|c|c|c|c|c|}
\hline \multirow[t]{2}{*}{ Country } & \multicolumn{2}{|c|}{ Bronchial responsiveness } & \multicolumn{2}{|c|}{ Atopy (serum IgE) } \\
\hline & Immigrants & Emigrants & Immigrants & Emigrants \\
\hline Australia & $1.22(0.72-2.06)$ & $1.70(0.50-5.83)$ & $0.79(0.51-1.20)$ & $0.70(0.23-2.15)$ \\
\hline Belgium & $3.83(1.41-10.44)^{*}$ & $\mathrm{nc}$ & $0.22(0.05-0.99)^{*}$ & $0.65(0.13-3.31)$ \\
\hline Denmark $^{\#}$ & $1.00(0.19-5.16)$ & nc & & \\
\hline France & $0.91(0.60-1.37)$ & $0.43(0.10-1.92)$ & $1.21(0.95-1.75)^{\oplus}$ & $1.01(0.35-2.89)$ \\
\hline Germany & $0.74(0.25-2.13)$ & $0.65(0.30-1.40)$ & $1.10(0.54-2.24)$ & $0.73(0.42-1.27)$ \\
\hline Iceland & $\mathrm{nc}$ & $\mathrm{nc}$ & 0.34 (0.04-2.77) & $6.08(0.32-116.1)$ \\
\hline Ireland & $1.17(0.31-4.40)$ & $1.00(0.11-8.24)$ & $3.01(1.04-8.70)^{*}$ & $1.63(0.68-2.09)$ \\
\hline Italy & $2.20(0.45-10.85)$ & $2.56(1.10-5.96)^{*}$ & $0.92(0.19-4.55)$ & $1.07(0.54-2.10)$ \\
\hline Netherlands & $\mathrm{nc}$ & $3.12(0.79-12.38)$ & $0.62(0.28-1.34)$ & $0.73(0.22-2.36)$ \\
\hline New Zealand & $0.90(0.55-1.47)$ & $1.14(0.22-6.03)$ & $0.82(0.51-1.34)$ & $1.19(0.33-4.31)$ \\
\hline Norway & $0.53(0.07-4.09)$ & $1.02(0.13-8.28)$ & $0.94(0.46-1.93)$ & $1.93(0.60-6.23)$ \\
\hline Spain & $0.61(0.14-2.61)$ & $0.86(0.20-3.80)$ & $1.69(0.74-3.84)$ & $0.65(0.24-1.76)$ \\
\hline Sweden & $0.62(0.32-1.22)$ & $0.97(0.12-8.05)$ & $0.95(0.66-1.36)$ & $0.29(0.04-2.36)$ \\
\hline Switzerland & $1.16(0.61-2.20)$ & $\mathrm{nc}$ & $0.95(0.63-1.44)$ & $0.88(0.20-3.59)$ \\
\hline UK & $0.50(0.19-1.29)$ & $1.22(0.76-1.98)$ & $0.68(0.38-1.23)$ & $0.86(0.57-1.29)$ \\
\hline USA & $1.19(0.31-4.58)$ & $0.34(0.08-1.54)$ & $4.05(1.39-11.80)^{*}$ & $0.37(0.12-1.14)^{\oplus}$ \\
\hline Total & $0.90(0.74-1.19)$ & $1.03(0.74-1.43)$ & $0.93(0.79-1.11)$ & $0.88(0.67-1.14)$ \\
\hline
\end{tabular}

Data are presented as OR $(95 \%$ confidence interval (CI)). IgE: immunoglobulin-E; nc: model did not achieve convergence due to lack of migrants. ${ }^{\#}$ : no data for IgE. *: $\mathrm{p}<0.05 ;$; : $\mathrm{p}<0.1$.

among immigrants, who might systematically report higher morbidity due to respiratory symptoms, similar to observations in some psychiatric surveys [17]. Indeed, misclassification of asthma for shortness of breath via anxiety and hyperventilation cannot be ruled out in any migration study of asthma. Within the present study, a report of shortness of breath was more frequent in migrants than nonmigrants both in a crude analysis (OR: 1.35, 95\% CI: $1.10-1.65)$ and in an analysis adjusted by country of residence, sex, age and smoking status (OR: 1.32, 95\% CI: 1.07-1.64) (data not shown). However, adjusted risks were not significantly increased in migrants for reported attack of asthma (OR: 1.09, 95\% CI: 0.85-1.42) and for currently taking medicines for asthma (OR: 1.08,
95\% CI: 0.81-1.44). The increased report of asthma in migrants is, therefore, unlikely to be due to a labelling or diagnostic bias. Language difficulties could lead to migrants having poor asthma education, and therefore poor compliance [18] and more symptoms. However, there is no evidence that the migrants in this study had less access to services (table 4).

A small number of published papers have assessed not only questionnaire data, but also other "harder" outcomes as in this study. Positivity to birch allergen by prick test and/or radioallergosorbent test in a survey performed in immigrants living in Sweden, was $16 \%$ in the persons who had been there $\sim 2.5 \mathrm{yrs}$ and increased to $53 \%$ in those who had been living there $>10.5$ yrs $[19,20]$. In contrast, LeUNG et al. [16] noted

Table 5.-Medication and use of health services of immigrants and emigrants compared with nonmigrants in subjects reporting asthma symptoms

\begin{tabular}{|c|c|c|c|c|c|}
\hline & \multicolumn{3}{|c|}{ No:yes } & \multicolumn{2}{|c|}{$\mathrm{OR}^{\#}(95 \% \mathrm{CI})$} \\
\hline & Nonmigrants & Immigrants & Emigrants & Immigrants & Emigrants \\
\hline \multicolumn{6}{|l|}{ Medication in last 12 months } \\
\hline Inhaled medicines & $704: 730$ & $79: 81$ & $27: 34$ & $0.98(0.70-1.38)$ & $1.11(0.66-1.88)$ \\
\hline Oral medicines & $960: 470$ & $94: 62$ & $38: 22$ & $1.41(1.00-1.99)^{*}$ & $1.15(0.66-1.98)$ \\
\hline Others & $1218: 218$ & $139: 20$ & $57: 4$ & $0.83(0.50-1.36)$ & $0.40(0.14-1.11)^{\bullet}$ \\
\hline \multicolumn{6}{|l|}{ Frequency of medication } \\
\hline Every day & 1198:217 & $123: 30$ & $46: 14$ & $1.38(0.90-2.12)$ & $1.60(0.86-2.97)$ \\
\hline Only for attacks & $796: 617$ & $81: 73$ & $31: 29$ & $1.22(0.87-1.72)$ & $1.17(0.69-1.98)$ \\
\hline \multicolumn{6}{|l|}{ Health services } \\
\hline Prescription by a doctor & 481:834 & 48:91 & $22: 39$ & $1.15(0.79-1.69)$ & $0.95(0.55-1.64)$ \\
\hline Ever visited hospital & 1137:298 & $124: 32$ & $47: 14$ & $0.98(0.64-1.49)$ & $1.14(0.62-2.11)$ \\
\hline Admitted to a hospital & $1246: 189$ & $141: 15$ & $51: 10$ & $0.72(0.41-1.27)$ & $1.23(0.61-2.49)$ \\
\hline Ever seen a doctor & $437: 996$ & $42: 113$ & $12: 48$ & $1.28(0.87-1.89)$ & $1.66(0.87-3.19)$ \\
\hline General practitioner & $753: 680$ & $75: 80$ & $26: 34$ & $1.24(0.88-1.74)$ & $1.41(0.83-2.39)$ \\
\hline Specialist & $1204: 229$ & $131: 24$ & $50: 10$ & $0.97(0.61-1.54)$ & $0.99(0.50-2.00)$ \\
\hline Other & $1360: 73$ & $150: 5$ & $58: 2$ & $0.66(0.26-1.68)$ & $0.69(0.16-2.88)$ \\
\hline
\end{tabular}

OR: odds ratio; CI: confidence interval. ${ }^{\#}$ : adjusted for sex, age and smoking. *: $\mathrm{p}<0.05 ;{ }^{\bullet}$ : $\mathrm{p}<0.1$. 
that both Asians born in Asia and Asians born in Australia had a much higher prevalence of atopy than Australians who were not of Asian origin (78.4\% and $81.0 \%$ versus $45.6 \%$ ), mainly due to sensitivity to pollen and mites. NonAsian Australians also had the lowest prevalence of hay fever, but the prevalence increased markedly with time since migration. However, non-Asian Australians had a higher prevalence of wheeze and asthma than Asian Australians who had been born in Australia, who, in turn, had higher rates than those who had been born in Asia. Among the migrants, there was a tendency for rates to increase with time since migration, though this increase was not significant after adjustment for age at arrival, sex and atopic status. Similarly, immigration to the Tucson (AZ, USA) area was a major factor in determining changes in skin reactivity prevalence to five allergens, from $39.1 \%$ at the initial survey to $50.7 \%$ after 8 yrs of follow-up [21]. Recently, ORMEROD et al. [22] observed that the prevalence of asthma was higher in those Asians born in the UK and in those who had lived in the UK for longest, but these associations were explained by the older age of these subjects.

To conclude, despite migrants reporting more symptoms associated with asthma than nonmigrants in the European Community Respiratory Health Survey, this study has to be considered as inconclusive. No consistency was observed when migrants moved to and from countries with high or low asthma, and no differences were observed in the level of bronchial responsiveness or atopy. In a recent editorial, it was stated that, in a civilized society, it is important that all those in need of healthcare should have equal access to it and benefit equally from that which is available [23]. Very importantly, the access to healthcare by migrants with symptoms of asthma seems no different to the nonmigrant population.

Acknowledgements. A. Tobias was a receiver of the 1999 GlaxoWellcome Summer Fellowship in Epidemiology based at Greenford, UK. The authors are grateful to the late C. Baya and M. Hallen for their help during the study and to $\mathrm{K}$. Vuylsteek and the members of the Comité d'Actions Concertées for their support. The co-ordination of this work was supported by the European Commission. Financial support: Allen and Hanbury's, Australia; Belgian Science Policy Office, National Fund for Scientific Research; Ministère de la Santé, Glaxo France, Insitut Pneumologique d'Aquitaine, Contrat de Plan Etat-Région LanguedocRousillon, CNMATS, CNMRT (90MR/10, 91AF/6), Ministre delegué de la santé, RNSP, France; GSF, and the Bundesminister für Forschung und Technologie, Bonn, Germany; The Greek Secretary General of Research and Technology, Fisons, Astra and BoehringerIngelheim; Bombay Hospital Trust, India; Ministero dell'Università e della Ricerca Scientifica e Tecnologica, CNR, Regione Veneto grant RSF n. 381/05.93, Italy; Asthma Foundation of New Zealand, Lotteries Grant Board, Health Research Council of New Zealand; Norwegian Research Council project no. 101422/310; Glaxo Farmace utica Lda, Sandoz, Portugal; Ministero
Sanidad y Consumo FIS (grants \#91/0016060/ 00E-05E and \#93/0393), and grants from Hospital General de Albacete, Hospital General Juan Ramón Jiménenz, Consejeria de Sanidad Principado de Asturias, Spain; The Swedish Medical Research Council, the Swedish Heart Lung Foundation, the Swedish Association against Asthma and Allergy; Swiss National Science Foundation grant 4026-28099; National Asthma Campaign, British Lung Foundation, Dept of Health, South Thames Regional Health Authority, UK; USA Dept of Health, Education and Welfare Public Health Service (grant \#2 S07 RR05521-28).

Co-ordinating Centre (London, UK): P. Burney,

S. Chinn, C. Luczynska, D. Jarvis, E. Lai.

Project Management Group: P. Burney (Project leader) S. Chinn, C. Luczynska, D. Jarvis, P. Vermeire (Antwerp), H. Kesteloot (Leuven), J. Bousquet (Montpellier), D. Nowak (Hamburg), the late J. Prichard (Dublin), R. de Marco (Verona), B. Rijcken (Groningen), J.M. Anto (Barcelona), J. Alves (Oporto), G. Boman (Uppsala), N. Nielsen (Copenhagen), P. Paoletti (Pisa).

Participating Centres: W. Popp (Vienna, Austria); M. Abramson, J. Kutin (Melbourne, Australia); P. Vermeire, F. van Bastelaer (Antwerp South, Antwerp Central, Belgium); J. Bousquet, J. Knani (Montpellier, France), F. Neukirch, R. Liard (Paris, France), I. Pin, C. Pison (Grenoble, France), A. Taytard (Bordeaux, France); H. Magnussen, D. Nowak (Hamburg, Germany); H-E. Wichmann, J. Heinrich (GSF Institute of Epidemiology, Erfurt, Germany); N. Papageorgiou, P. Avarlis, M. Gaga, C. Marossis (Athens, Greece); T. Gislason D. Gislason (Reykjavik, Iceland); J. Prichard, S. Allwright, D. MacLeod (Dublin, Ireland); M. Bugiani, C. Bucca, C. Romano (Turin, Italy) R. de Marco, V. Lo Cascio, C. Campello (Verona, Italy) A. Marinoni, I. Cerveri, L. Casali (Pavia, Italy); B. Rijcken, A. Kremer (Groningen, Bergen-op-Zoom, Geleen, the Netherlands); J. Crane, S. Lewis (Wellington, Christchurch, Hawkes Bay, New Zealand); A. Gulsvik, E. Omenaas (Bergen, Norway); J.A. Marques, J. Alves (Oporto, Portugal); Spain: J.M. Antó, J. Sunyer, F. Burgos, J. Castellsagué, J. Roca, J.B. Soriano, A. Tobías (Barcelona, Spain), N. Muniozguren, J. Ramos González, A. Capelastegui (Galdakao, Spain) J. Castillo, J. Rodriguez Portal (Seville, Spain), J. MartinezMoratalla, E. Almar (Albacete, Spain) J. Maldonado Pérez, A. Pereira, J. Sánchez (Huelva, Spain), J. Quiros, I. Huerta, F. Pavo (Oviedo, Spain); G. Boman, C. Janson, E. Björnsson (Uppsala, Sweden), L. Rosenhall, E. Norrman, B. Lundbäck (Umeå, Sweden), N. Lindholm, P. Plaschke (Göteborg, Sweden); U. Ackermann-Liebrich, N. Künzli, A. Perruchoud (Basel, Switzerland); M. Burr, J. Layzell (Caerphilly, UK), R. Hall (Ipswich, UK), B. Harrison (Norwich, UK), J. Stark (Cambridge, UK); S. Buist, W. Vollmer, M. Osborne (Portland, USA).

\section{References}

1. Leung R. Asthma and migration. Respirology 1996; 1: 123-126.

2. Cavalli-Sforza L, Menozzi P, Piazza A, eds. The 
History and Geography of Human Genes. Princeton, Princeton University Press, 1996.

3. Schreiber S. Migration, traumatic bereavement and transcultural aspects of psychological healing: loss and grief of a refugee woman from Begameder county in Ethiopia. Brit J Med Psychol 1995; 68: 135-142.

4. Kogevinas M, Anto JM, Tobias A, et al. Respiratory symptoms, lung function and use of health services among unemployed young adults in Spain. Spanish Group of the European Community Respiratory Health Survey. Eur Respir J 1998; 11: 1363-1368.

5. European Community Respiratory Health Survey. Variations in the prevalence of respiratory symptoms, self-reported asthma attacks, and use of asthma medication in the European Community Respiratory Health Survey (ECRHS). Eur Respir J 1996; 9: 687695.

6. Burney P, Malmberg E, Chinn S, Jarvis D, Luczynska C, Lai E. The distribution of total and specific serum $\mathrm{IgE}$ in the European Community Respiratory Health Survey. J Allergy Clin Immunol 1997; 99: 314-322.

7. Chinn S, Burney P, Jarvis D, Luczynska C. Variation in bronchial responsiveness in the European Community Respiratory Health Survey (ECRHS). Eur Respir $J$ 1997; 10: 2495-2501.

8. Kogevinas M, Anto JM, Sunyer J, Tobias A, Kromhout $\mathrm{H}$, Burney P. Occupational asthma in Europe and other industrialised areas: a population-based study. European Community Respiratory Health Survey Study Group. Lancet 1999; 353: 1750-1754.

9. Burney PGJ, Luczynska C, Chinn S, Jarvis D. The European Community Respiratory Health Survey. Eur Respir J 1994; 7: 954-960.

10. StataCorp. Stata Statistical Software. Release 6.0. College Station, Texas, Stata Corporation, 1999.

11. Hosmer DW, Lemeshow S. Applied Logistic Regression. New York, John Wiley and Sons, 1989.

12. DerSimonian R, Laird N. Meta-analysis in clinical trials. Control Clin Trials 1986; 7: 177-188.
13. Janson C, Chinn S, Jarvis D, Burney P. Physiciandiagnosed asthma and drug utilization in the European Community Respiratory Health Survey. Eur Respir J 1997; 10: 1795-1802.

14. Janson C, Chinn S, Jarvis D, Burney P. Individual use of antiasthmatic drugs in the European Community Respiratory Health Survey. Eur Respir J 1998; 12: 557-563.

15. Strachan DP, Golding J, Anderson HR. Regional variations in wheezing illness in British children: effect of migration during early childhood. J Epidemiol Community Health 1990; 44: 231-236.

16. Leung RC, Carlin JB, Burdon JGW, Czarny D. Asthma, allergy and atopy in Asian immigrants in Melbourne. Med J Aust 1994; 161: 418-425.

17. Finlay-Jones RA, Burvill PW. The prevalence of minor psychiatric morbidity in the community. Psychol Med 1977; 7: 475-489.

18. Ayres JG. Acute asthma in Asian patients: hospital admissions and duration of stay in a district with a high immigrant population. Br J Dis Chest 1986; 80: 242-248.

19. Kalyoncu AF. Is immigration a prognostic factor for oral allergy syndrome in patients with birch pollen hypersensitivity? J Allergy Clin Immunol 1996; 98: 1135.

20. Kalyoncu AF, Stalenheim G. Serum IgE levels and allergic spectra in immigrants to Sweden. Allergy 1992; 47: 277-280.

21. Barbee RA, Kaltenborn W, Lebowitz MD, Burrows B. Longitudinal changes in allergen skin test reactivity in a community population sample. J Allergy Clin Immunol 1987; 79: 16-24.

22. Ormerod LP, Myers P, Prescott RJ. Prevalence of asthma and 'probable' asthma in the Asian population in Blackburn, UK. Respir Med 1999; 93: 16-20.

23. Partridge MR. In what way may race, ethnicity or culture influence asthma outcomes? Thorax 2000; 55: $175-176$. 